\title{
Effects of low-dose clonidine on cardiovascular and autonomic variables in adolescents with chronic fatigue: a randomized controlled trial
}

Even Fagermoen ${ }^{1,2^{*}}$, Dag Sulheim ${ }^{3,4}$, Anette Winger ${ }^{5}$, Anders M. Andersen ${ }^{6}$, Johannes Gjerstad ${ }^{7,8}$, Kristin Godang $^{9}$, Peter C. Rowe ${ }^{10}$, J. Philip Saul ${ }^{11}$, Eva Skovlund ${ }^{12,13}$ and Vegard Bruun Wyller ${ }^{1,14}$

\begin{abstract}
Background: Chronic Fatigue Syndrome (CFS) is a common and disabling condition in adolescence with few treatment options. A central feature of CFS is orthostatic intolerance and abnormal autonomic cardiovascular control characterized by sympathetic predominance. We hypothesized that symptoms as well as the underlying pathophysiology might improve by treatment with the alpha $2 \mathrm{~A}$-adrenoceptor agonist clonidine.
\end{abstract}

Methods: A total of 176 adolescent CFS patients (12-18 years) were assessed for eligibility at a single referral center recruiting nation-wide. Patients were randomized 1:1 by a computer system and started treatment with clonidine capsules $(25 \mu \mathrm{g}$ or $50 \mu \mathrm{g}$ twice daily, respectively, for body weight below/above $35 \mathrm{~kg}$ ) or placebo capsules for 9 weeks. Double-blinding was provided. Data were collected from March 2010 until October 2012 as part of The Norwegian Study of Chronic Fatigue Syndrome in Adolescents: Pathophysiology and Intervention Trial (NorCAPITAL). Effect of clonidine intervention was assessed by general linear models in intention-to-treat analyses, including baseline values as covariates in the model.

Results: A total of 120 patients (clonidine group $n=60$, placebo group $n=60$ ) were enrolled and started treatment. There were 14 drop-outs ( 5 in the clonidine group, 9 in the placebo group) during the intervention period. At 8 weeks, the clonidine group had lower plasma norepinephrine (difference $=205 \mathrm{pmol} / \mathrm{L}, \mathrm{p}=0.05$ ) and urine norepinephrine/ creatinine ratio (difference $=3.9 \mathrm{nmol} / \mathrm{mmol}, p=0.002$ ). During supine rest, the clonidine group had higher heart rate variability in the low-frequency range (LF-HRV, absolute units) (ratio $=1.4, p=0.007$ ) as well as higher standard deviation of all RR-intervals (SDNN) (difference $=12.0 \mathrm{~ms}, \mathrm{p}=0.05$ ); during $20^{\circ}$ head-up tilt there were no statistical differences in any cardiovascular variable. Symptoms of orthostatic intolerance did not change during the intervention period.

Conclusions: Low-dose clonidine reduces catecholamine levels in adolescent CFS, but the effects on autonomic cardiovascular control are sparse. Clonidine does not improve symptoms of orthostatic intolerance.

Trial registration: Clinical Trials ID: NCT01040429, date of registration 12/28/2009.

\footnotetext{
* Correspondence: feef@online.no

${ }^{1}$ Institute of Clinical Medicine, Medical Faculty, University of Oslo, P.O.Box

1171, Blindern 03180slo, Norway

2Department of Anaesthesiology and Critical Care, Oslo University Hospital,

P.O.Box 4950, Nydalen 04240slo, Norway

Full list of author information is available at the end of the article
}

C Biomed Central (c) 2015 Fagermoen et al. Open Access This article is distributed under the terms of the Creative Commons Attribution 4.0 International License (http://creativecommons.org/licenses/by/4.0/), which permits unrestricted use, distribution, and reproduction in any medium, provided you give appropriate credit to the original author(s) and the source, provide a link to the Creative Commons license, and indicate if changes were made. The Creative Commons Public Domain Dedication waiver (http://creativecommons.org/publicdomain/zero/1.0/) applies to the data made available in this article, unless otherwise stated. 


\section{Background}

Chronic Fatigue Syndrome (CFS) is a disabling condition with unknown pathophysiology. In adolescents, prevalence has been estimated from 0.1 to $2.4 \%$ depending on definition of CFS and method of estimation [1, 2]. Apart from a single trial of intravenous immunoglobulin in adolescents with CFS [3], no pharmacotherapy has proven beneficial in this patient population.

Orthostatic intolerance is common with a prevalence of more than $25 \%$ in adults with CFS [4], and more than $90 \%$ in children with CFS [5, 6]. Previously, dysregulation of autonomic cardiovascular control has been demonstrated in adults as well as adolescents, characterized by increased sympathetic and decreased parasympathetic nervous activity [7-10]. This autonomic imbalance might reflect alteration of central control mechanism [11, 12], and provide a target for pharmacotherapy $[7,13]$.

Clonidine is a centrally acting agonist to the presynaptic alpha $_{2 \mathrm{~A}}$ receptor, thereby attenuating sympathetic nervous activity and enhancing parasympathetic activity, even in low doses [14-16]. Thus, clonidine has well-known antihypertensive properties. A pilot study suggested normalization of cardiovascular variables in adolescent CFS patients receiving low-dose clonidine [17]. However, a single nucleotide polymorphism (SNP) of the alpha $_{2 \mathrm{~A}}$ receptor gene might possible modify the effect of clonidine treatment [18].

The aim of this study was to investigate the effects of low-dose clonidine on autonomic cardiovascular control in adolescent CFS. We hypothesized that clonidine would improve symptoms of orthostatic intolerance and normalize cardiovascular variables and indices of autonomic nervous activity at rest as well as during orthostatic challenges. The study is part of the NorCAPITAL-project (The Norwegian Study of Chronic Fatigue Syndrome in Adolescents: Pathophysiology and Intervention Trial; ClinicalTrials ID: NCT01040429, date of registration 12/28/2009).

\section{Methods}

\section{Patients}

All hospital pediatric departments in Norway $(n=20)$ as well as primary care pediatricians and general practitioners were invited to refer patients aged $12-18$ years to the national referral center for young CFS patients at Oslo University Hospital. The referring units were equipped with written information for distribution to potential study participants and their parents/next-of-kin. If consent was given, a standard form required the referral unit to confirm the result of clinical investigations considered compulsory to diagnose pediatric CFS according to national Norwegian recommendations (pediatric specialist assessment, comprehensive hematology and biochemistry analyses, chest $\mathrm{x}$-ray, abdominal ultrasound, and brain magnetic resonance imaging). Also, the referring units were required to confirm that the patient a) was unable to follow normal school routines due to fatigue; b) was not permanently bedridden; c) did not have any concurrent medical or psychiatric disorder that might explain the fatigue; d) did not experience any concurrent demanding life event (such as parents' divorce) that might explain the fatigue; e) did not use prescribed pharmaceuticals (including hormone contraceptives) regularly. A previous demanding life event was not an exclusion criterion. Completed forms were consecutively conveyed to the study center and carefully evaluated by either of two authors (DS or EF). Patients considered eligible to this study were invited to a clinical encounter at our study center after which a final decision on inclusion was made.

In agreement with clinical guidelines [19, 20], this study applied a "broad" case definition of CFS, requiring three months of unexplained, disabling chronic/relapsing fatigue of new onset. We did not require that patients meet any other accompanying symptom criteria. Details of inclusion and exclusion criteria are provided in Table 1.

\section{Study design}

All included patients underwent a baseline investigational program at our research unit. Thereafter, they were randomized to 9 weeks of treatment with oral clonidine capsules or placebo capsules in a 1:1 ratio, using a computer-based routine for stratified randomization (block size: 4); 18 months disease duration (the median disease duration in a previous follow-up study [21]) served as the stratification criterion. Because of practical issues, randomization was performed prior to final decision on enrolment; the procedure was carried out by a research nurse not otherwise affiliated with the study. Outcome was assessed by an investigational program identical to the baseline program at week 8 and week 30; in this article, only results from week 8 are reported. Patients and researchers were blinded to treatment allocation at all stages.

Clonidine dosages were $50 \mu \mathrm{g}$ B.I.D for body weight $>35 \mathrm{~kg}$, and $25 \mu \mathrm{g}$ B.I.D for body weight $<$ $35 \mathrm{~kg}$. Catapresan $25 \mu \mathrm{g}$ clonidine hydrochloride tablets (Boehringer Ingelheim, Germany) were enclosed in orange opaque, demolition-restraint lactose capsules (Apoteket Produktion \& Laboratorier, Kungens Kurva, Sweden). Identical capsules without Catapresan ${ }^{\circ}$ were used as placebo comparator. Half the dose was given for the first 3 days of the intervention period in order to minimize adverse introductory effects. Blood samples for clonidine concentration analyses were taken approximately two weeks after start of the intervention, and at the second visit.

NorCAPITAL was approved by the Norwegian National Committee for Ethics in Medical Research and the Norwegian Medicines Agency. Data were collected 
Table 1 Criteria for inclusion and exclusion

\begin{tabular}{|c|c|c|}
\hline & Inclusion criteria & Exclusion criteria \\
\hline \multirow[t]{14}{*}{ CFS patients } & $\begin{array}{l}\text { Persisting or constantly relapsing fatigue lasting } \\
3 \text { months or more. }\end{array}$ & $\begin{array}{l}\text { Another current disease process or demanding life event } \\
\text { that might explain the fatigue }\end{array}$ \\
\hline & $\begin{array}{l}\text { Functional disability resulting from fatigue to a } \\
\text { degree that prevent normal school attendance }\end{array}$ & Another chronic disease \\
\hline & \multirow[t]{12}{*}{ Age $\geq 12$ years and $<18$ years } & $\begin{array}{l}\text { Permanent use of drugs (including hormones) possibly } \\
\text { interfering with measurements }\end{array}$ \\
\hline & & Permanently bed-ridden \\
\hline & & Positive pregnancy test \\
\hline & & Pheocromocytoma \\
\hline & & $\begin{array}{l}\text { Evidence of reduced cerebral and/or peripheral circulation } \\
\text { due to vessel disease }\end{array}$ \\
\hline & & Polyneuropathy \\
\hline & & Renal insufficiency \\
\hline & & $\begin{array}{l}\text { Known hypersensitivity towards clonidine or inert substances } \\
\text { (lactose, saccarose) in capsule }\end{array}$ \\
\hline & & Abnormal ECG (apart from ectopic beats) \\
\hline & & Supine heart rate $<50$ beats/min \\
\hline & & Supine systolic blood pressure $<85 \mathrm{mmHg}$ \\
\hline & & Upright systolic blood pressure fall $>30 \mathrm{mmHg}$ \\
\hline \multirow[t]{2}{*}{ Healthy control subjects } & \multirow[t]{2}{*}{ Age $\geq 12$ years and $<18$ years } & Another chronic disease \\
\hline & & Permanent use of drugs (including hormones) \\
\hline
\end{tabular}

in the period March 2010 until October 2012. Written informed consent was obtained from all participants, and from parents/next-of-kin if required.

\section{Investigational program}

A one-day in-hospital assessment included clinical examination, blood sampling (antecubital venous puncture), and $20^{\circ}$ head-up tilt test (HUT), and always commenced between 7.30 and 9.30 a.m. Patients were instructed to fast overnight and abstain from tobacco products and caffeine for at least $48 \mathrm{~h}$, to bring a morning spot urine sample in a sterile container, and to apply the local anesthetic lidocaine $\left(\mathrm{Emla}^{\circ}\right)$ on the skin in the antecubital area one hour in advance. At week 8, CFS patients were told to postpone their prescribed morning study drug dose (clonidine/placebo) until after blood sampling and HUT. All procedures were undertaken in a quiet, warm room in a fixed sequence and by three researchers only (DS, EF and AW). Blood samples were obtained in a fixed sequence from antecubital venous puncture after at least five minutes supine rest in calm surroundings. Samples of oral mucosa were collected for genetic analyses. Following the in-hospital assessment, a self-administered questionnaire was completed.

\section{Laboratory analyses}

The blood samples for plasma norepinephrine (NA) and epinephrine (A) analyses were obtained in vacutainer tubes treated with ethylene glycol tetraacetic acid (EGTA)-Glutathione. The samples were placed on ice for approximately $30 \mathrm{~min}$; thereafter, plasma was separated by centrifugation $\left(3000 \mathrm{rpm}, 15 \mathrm{~min}, 4{ }^{\circ} \mathrm{C}\right.$ ) and frozen at $80{ }^{\circ} \mathrm{C}$ until assayed. Samples were analyzed for plasma NA and $\mathrm{A}$ by high-performance liquid chromatography (HPLC) with a reversed-phase column and glassy carbon electrochemical detector (Antec, Leyden Deacade II SCC, Zoeterwoude, The Netherlands) using a commercial kit (Chromsystems, München, Germany) [22-24]. All samples were measured in singlet, with serial samples from a given individual run at the same time to minimize run-torun variability. The intra- and interassay coefficient of variation $(\mathrm{CV})$ were 3.9 and $10.8 \%$, respectively. The detection limit was $5.46 \mathrm{pM}$.

Urine samples for NA and A analyses were collected in $10 \mathrm{ml}$ universal containers. Immediately after collection the urine was acidified to $\mathrm{pH} \approx 2.5$, thereafter, stored at $2-8{ }^{\circ} \mathrm{C}$ until assayed. Urine treated this way is stable at least 5 days. The analyses were performed consecutively. The same HPLC protocol as for plasma measurement was used for the measurement of urin NA/A. The intra- and interassay coefficient of variation $(\mathrm{CV})$ for urine were 3.9 and $5.2 \%$, respectively.

The blood samples for clonidine determinations were collected in $4 \mathrm{~mL}$ heparin tubes. After centrifugation for $12 \mathrm{~min}$ at $1000 \mathrm{~g}$ at room temperature, the plasma fraction was frozen at $-20{ }^{\circ} \mathrm{C}$ until analysis. A slight 
modification of the method described by Müller et al. [25] was used for plasma clonidine assaying. The assay was validated based on FDA guidelines [26]. The samples were separated on an Alliance HT 2795 HPLC system and detected by a Micromass Quattro micro API MS/MS-instrument. System control, data acquisition and integration were performed by Masslynx software Ver 4.1.2008 (all from Waters, Milford, MA, USA). The MS/MS conditions were optimized by manual tuning during pump-infusion of neat solutions. The assay was set up to quantify from $0.10 \mu \mathrm{g} /$ $\mathrm{L}$ to $5.00 \mu \mathrm{g} / \mathrm{L}$ clonidine in plasma. Quality control samples were included in all sample series, and placed both before and after the patient samples in each analytical run. The median intra assay CV was $1 \%$ at $5 \mu \mathrm{g} / \mathrm{L}, 5 \%$ at $0.75 \mu \mathrm{g} / \mathrm{L}$ and $10 \%$ at $0.10 \mu \mathrm{g} / \mathrm{L}$. The inter assay $\mathrm{CV}$ was $6 \%$ at $5 \mu \mathrm{g} / \mathrm{L}, 5 \%$ at $0.75 \mu \mathrm{g} / \mathrm{L}$ and $12 \%$ at $0.10 \mu \mathrm{g} / \mathrm{L}$. Limit of detection, defined as a peak-to-peak signal to noise ratio of $5: 1$, verified by the Masslynx software, was $0.025 \mu \mathrm{g} / \mathrm{L}$. Accuracy was $97 \%$ (median) at $5 \mu \mathrm{g} / \mathrm{L}, 97 \%$ at $0.75 \mu \mathrm{g} / \mathrm{L}$, and $107 \%$ at $0.10 \mu \mathrm{g} / \mathrm{L}$.

The genotyping of the alpha $\mathrm{IA}_{\mathrm{A}}$ receptor single nucleotide polymorphism (SNP) rs1800544 was carried out by predesigned TaqMan SNP genotyping assay (Applied Biosystems, Foster City, CA, USA), using the SDS 2.2 software (Applied Biosystems). As previously described, approximately $10 \%$ of the samples were re-genotyped, and the concordance rate was $100 \%$ [27]. Genotyping was also performed in 68 healthy individuals having the same distribution of gender and age as the CFS patients.

\section{Head-up tilt-test}

Head-up tilt-test (HUT) was performed using an electronically operated tilt table with foot-board support (Model 900-00, CNSystems Medizintechnik, Graz, Austria). Patients were connected to the Task Force Monitor (TFM) (Model 3040i, CNSystems Medizintechnik, Graz, Austria), a combined hardware and software device for noninvasive recording of cardiovascular variables. 5 min was used for supine recordings, after which the participants were head-up tilted to $20^{\circ}$ for $15 \mathrm{~min}$. Details of the HUT protocol have been described elsewhere [9]. The feasibility of this protocol for studying adolescent CFS patients has been demonstrated in several previous studies $[9,28]$. In particular, the low tilt angle $\left(20^{\circ}\right)$ does not normally precipitate syncope, which is otherwise a common problem among adolescents being subjected to stronger orthostatic challenges [29]. Still, $20^{\circ}$ head-up tilt is sufficient to demonstrate hemodynamic alterations and compensatory autonomic responses.

Instantaneous RR intervals (RRI) and heart rate (HR) were obtained from the electrocardiogram (ECG). Continuous arterial blood pressure was obtained noninvasively using photoplethysmography on the right middle finger. Mean arterial blood pressure (BP) was calculated by numerical integration of the recorded instantaneous BP. The recorded value was calibrated against conventional oscillometric measurements of arterial BP on the left arm every five minutes according to the TFM manufacturer's recommendation. Impedance cardiography with electrodes placed on the neck and upper abdomen was used to obtain a continuous recording of the temporal derivative of the transthoracic impedance $(\mathrm{dZ} / \mathrm{dt})$. Beatto-beat stroke volume was calculated from the impedance signal [30].

Power spectral analysis (frequency-domain method) of HR variability and systolic blood pressure (SBP) variability was automatically provided by the TFM, using an adaptive autoregressive model [31]. Power was calculated in the Low Frequency (LF) range (0.05 to $0.17 \mathrm{~Hz})$, and High Frequency (HF) range $(0.17$ to $0.4 \mathrm{~Hz})$. In addition, time-domain indices of variability were computed from the RRIs: The standard deviation of all RRintervals (SDNN), the proportion of successive RRIs with a difference greater than $50 \mathrm{~ms}$ (pNN50), and the square root of the mean square differences of successive RRIs (r-MSSD).

Heart rate variability (HRV) is considered an index of autonomic cardiac modulation. In the frequency-domain, vagal (parasympathetic) activity is the main contributor to HF variability, whereas both vagal and sympathetic activity contributes to LF variability [32]. The LF/HF ratio is considered an index of sympathovagal balance. SBP variability is regarded an index of sympathetic modulation of peripheral resistance vessels [33]. For time-domain indices, vagal (parasympathetic) activity is the main contributor to pNN50 and r-MSSD, whereas SDNN is a measure of total variability, analogous to the Total Power index in the frequency domain.

Data from each HUT procedure was exported to Microsoft Excel for further calculations. Beat-to-beat stroke index (SI) was calculated dividing stroke volume by body surface area, and beat-to-beat total peripheral resistance index (TPRI) was calculated as mean BP divided by the product of SI and HR. For each participant, the following epochs of the recordings were chosen: Baseline (270 to $30 \mathrm{~s}$ before tilt up) and Early tilt (30 to $270 \mathrm{~s}$ after tilt). In each epoch we computed the median value for the conventional cardiovascular variables as well as the indices of HR and SBP variability; this procedure reduces the influence of erroneous outliers, such as ectopic heart beats. Thereafter, the delta values (Early Tilt - Baseline) which are considered indices of the cardiovascular response to orthostatic challenge were computed for each participant. This analytic approach has been proven feasible in several previous report from our group [9-11]. 


\section{Questionnaire}

The participants received a comprehensive questionnaire consisting of several validated inventories, as has been described in detail elsewhere [28].

The Autonomic Symptom Profile (ASP) [34], which has been used in previous Norwegian CFS studies but which is not validated for the Norwegian language, was slightly modified in order to fit our age group. A composite score reflecting orthostatic symptoms was constructed from 8 single items from the ASP, addressing experiences of dizziness in specific situations (such as rising suddenly from supine position, taking a shower, etc.). The total sum score is from 0 to 8 ; higher values reflect more pronounced orthostatic problems. In addition, other symptoms related to autonomic cardiovascular control, such as palpitations and pale and cold hands, were charted on a 1-5 Likert scale.

The questionnaire also included the CFS symptom inventory for adolescents [28, 35]. This inventory was used to subgroup the CFS patients according to the 1994 CFS case definition [36].

\section{Statistics}

Determination of sample size is described elsewhere [28]. Outcome of clonidine intervention was assessed by general linear models (ANCOVA) in intention-to-treat analyses, including baseline values as covariates in the model [37]. The net intervention effect was calculated from the parameters of the fitted general linear model. Differential effects in subgroups adhering to the 1994 CFS case definition, genotype of the alpha $2 \mathrm{~A}$ receptor single nucleotide polymorphism (SNP) rs1800544, and sex, were explored by including these variables as interaction terms. Dose-response relationships for patients allocated to clonidine were explored by linear regression analyses. Missing values were imputed as last observation carried forward from the pre-medication test. In order to obtain near-normally distributed variables, In-transformation was carried out for supine values of LF-HRV, HF-HRV, Total Power-HRV, LF/HF ratio and LF-SBP. Square root transformation was carried out for $20^{\circ}$ head-up tilt values of LF-HRV, HF-HRV and Total Power-HRV. Genotype frequency among patients and healthy controls were explored with chi-square analyses.

SPSS statistical software (SPSS Inc., Chicago, IL, USA) was applied for all statistical analyses, and all tests were carried out two-sided. A p-value $\leq 0.05$ was considered statistically significant. Corrections for multiple comparisons were not applied.

\section{Results}

A total of 176 CFS patients were referred to the study, of which 151 were eligible for randomization (Fig. 1). A total of 120 patients were enrolled and started treatment; 60 patients in the clonidine group and 60 patients in the placebo group. At week 8 , there were 5 dropouts in the clonidine group and 9 dropouts in the placebo group (Fig. 1). Further baseline demographic and clinical characteristics are given in Table 2 .

At week 8 , the clonidine group had statistically significantly lower plasma norepinephrine $(p=0.05)$ and urine norepinephrine/creatinine ratio $(p=0.002)$ as compared to the placebo group (Table 3 ). At supine rest, the clonidine group had higher heart rate variability in the lowfrequency band (LF-HRV, absolute unites) $(p=0.007)$ and as well as higher $\operatorname{SDNN}(p=0.05)$ (Table 4$)$. No other significant differences were observed. In particular, symptoms of orthostatic intolerance did not change during the intervention period.

Urine norepinephrine/creatinine ratio was negatively related to plasma clonidine concentration $(B=-14.5$, $p=0.004)$. TPRI supine $(B=4.1, p=0.01)$, heart rate variability in the low-frequency band supine (LF-HRV, absolute unites $)(B=1423, p=0.02)$ and HRV-Total Power supine $(B=4353, p=0.04)$ were positively related to plasma clonidine concentration. No other dose response-relationships were found.

Subgrouping according to the 1994 CFS case definition, genotype frequency of the alpha $_{2 \mathrm{~A}}$ receptor SNP rs1800544 and sex did not reveal any differential response to the intervention. Also, the genotype frequency was equal among CFS patients and healthy controls $(p=0.75)$.

\section{Discussion}

This study shows that clonidine reduces catecholamine levels in adolescent CFS. However, the effects on cardiovascular autonomic control are sparse, and clonidine does not improve symptoms of orthostatic intolerance.

Previous studies have documented that adult as well as adolescent CFS patients are characterized by enhanced sympathetic and attenuated parasympathetic nervous activity [7, 9, 38, 39]. In particular, CFS patients have increased levels of catecholamines $[40,41]$ and a sympathetic predominance of cardiovascular autonomic control possibly due to central alterations $[9,11,42]$. In this study, clonidine lowered catecholamine levels as expected. Of note, urine norepinephrine, which is considered an index of sympathetic nervous activity over time [43], decreased dose-dependently.

Clonidine had limited impact on standard cardiovascular variables, both at rest and during orthostatic challenge. This finding was surprising. In previous studies of healthy individuals as well as hypertensive patients, clonidine dosages similar to those applied in this study have been shown to decrease both blood pressures and heart 


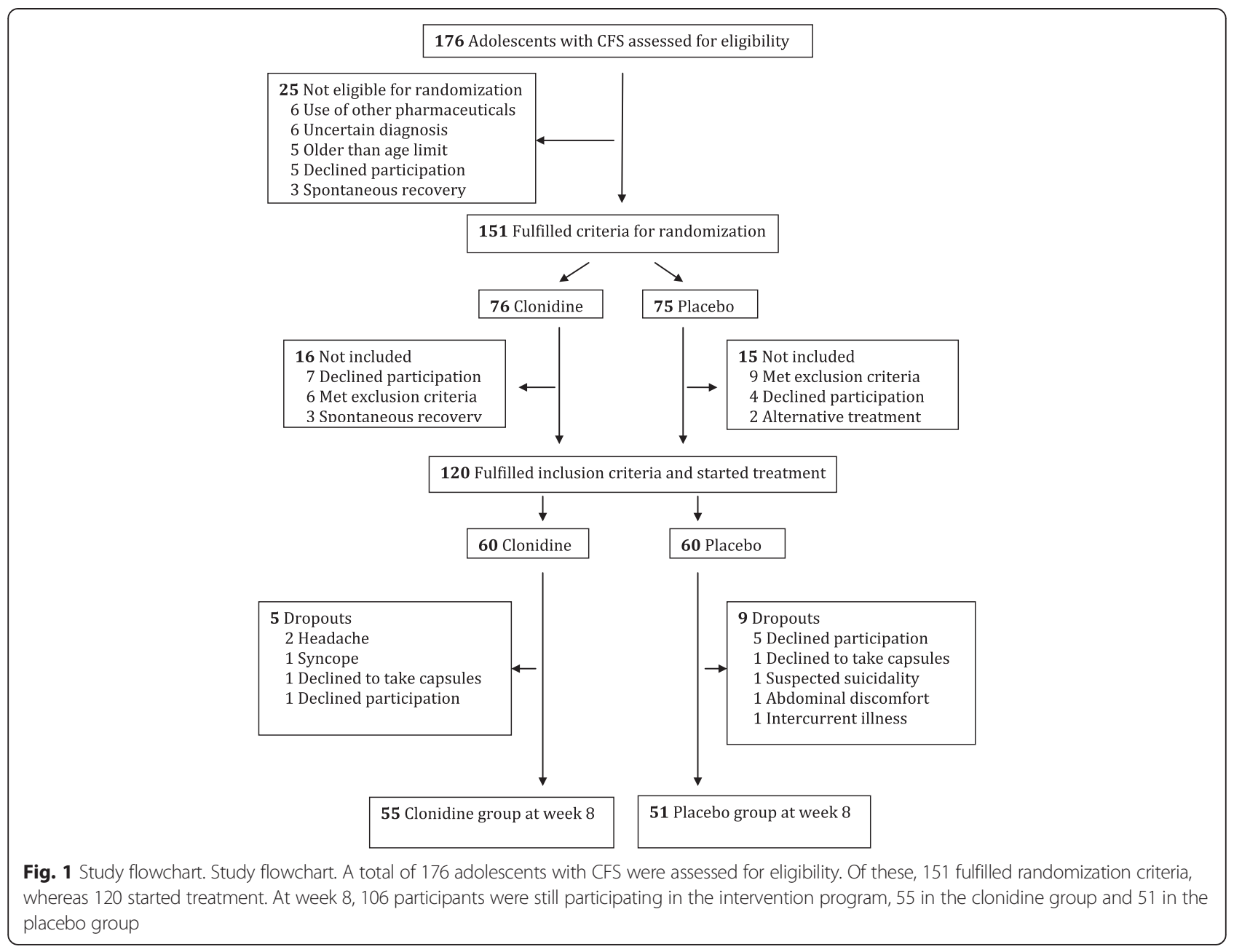

Table 2 Background characteristics

\begin{tabular}{|c|c|c|}
\hline & Clonidine $(n=60)$ & Placebo $(n=60)$ \\
\hline \multicolumn{3}{|l|}{ Gender - no. (\%) } \\
\hline Male & $13(22)$ & $21(35)$ \\
\hline Female & $47(78)$ & $39(65)$ \\
\hline Age - years, mean $\pm S D$ & $15.3 \pm 1.5$ & $15.5 \pm 1.6$ \\
\hline $\mathrm{BMI}-\mathrm{kg} / \mathrm{m}^{2}$, mean $\pm \mathrm{SD}$ & $21.6 \pm 4.4$ & $21.5 \pm 4.0$ \\
\hline \multicolumn{3}{|l|}{ Adheres to 1994 CFS case definition - no. (\%) } \\
\hline No & $14(24)$ & $15(26)$ \\
\hline Yes & $45(76)$ & $43(74)$ \\
\hline \multicolumn{3}{|l|}{ Genotype $^{a}-$ no. (\%) } \\
\hline $\mathrm{C} / \mathrm{C}$ & $32(53)$ & $35(58)$ \\
\hline$C / G$ & $25(42)$ & $19(32)$ \\
\hline $\mathrm{G} / \mathrm{G}$ & $3(5)$ & $6(10)$ \\
\hline Disease duration - months, median (range) & 18 (4 to 72$)$ & $18(5$ to 104$)$ \\
\hline Disease duration - months, mean \pm SD & $19.4 \pm 13.0$ & $23.5 \pm 17.0$ \\
\hline School absenteism - \%, mean \pm SD & $66 \pm 29$ & $64 \pm 31$ \\
\hline Smokers - more than once a week - no. & 1 & 0 \\
\hline
\end{tabular}

${ }^{\mathrm{a}}$ The alpha ${ }_{2 \mathrm{~A}}$ receptor single nucleotide polymorphism (SNP) rs1800544. C = Cytosine, G = Guanine 
Table 3 Outcome of clonidine intervention - symptom scores and catecholamines

Symptoms scores

Orthostatic symptoms - total score

Clonidine group, mean

Placebo group, mean

Difference $(95 \% \mathrm{Cl})$

p-value (clonidine vs. placebo)

Palpitations - score

Clonidine group, mean

Placebo group, mean

Difference $(95 \% \mathrm{Cl})$

p-value (clonidine vs. placebo)

Pale and cold hands - score

Clonidine group, mean

Placebo group, mean

Difference $(95 \% \mathrm{Cl})$

p-value (clonidine vs. placebo)

Catecholamines

Plasma norepinephrine - pmol/L

Clonidine group, mean

Difference $(95 \% \mathrm{Cl})$

p-value (clonidine vs. placebo)

Plasma epinephrine - pmol/L

Clonidine group, mean

Placebo group, mean

Difference $(95 \% \mathrm{Cl})$

p-value (clonidine vs. placebo)

Urine norepinephrine/creatinine ratio - $\mathrm{nmol} / \mathrm{mmol}$

Clonidine group, mean

Placebo group, mean

Difference $(95 \% \mathrm{Cl})$

p-value (clonidine vs. placebo)

Urine epinephrine/creatinine ratio - $\mathrm{nmol} / \mathrm{mmol}$

Clonidine group, mean

Placebo group, mean

Difference $(95 \% \mathrm{Cl})$

p-value (clonidine vs. placebo)

3.0

3.0

327

415

1.7

1.6

$\begin{array}{ll}3.8 & 3.5\end{array}$

$3.5 \quad 3.5$

-0.05 ( -0.5 to 0.4$)$

0.84

2.2

2.2

0.06 ( -0.3 to 0.4$)$

0.73

2.7

2.8

$-0.1(-0.5$ to 0.3$)$

0.62

1557

1761

$-205(-406$ to -4$)$

0.05

291

299

-8 ( -44 to 29$)$

0.68

9.6

13.6

$-3.9(-6.4$ to -1.5$)$

0.002

1.2

1.6

$-0.4(-0.8$ to 0.1$)$

0.11

Missing values were imputed based on the principle of last observation carried forwards. Thus, all calculations are based on 120 individuals (60 in each intervention group except one to two in each group with missing values at baseline). Means and differences at week 8 are estimated from the parameters of the general linear model

rate, and these alterations of hemodynamics were paralleled by a decrement of catecholamines [15, 44-47]. Furthermore, in healthy subjects, clonidine also attenuates indices of cardiovascular sympathetic nervous modulation (such as LF-HRV), both in supine and sitting positions [44]. In this study, there was a clonidinemediated increase in LF-HRV at supine rest, as well as a positive relationship between LF-HRV and clonidine plasma concentration. The interpretation of LF-HRVindices is not straight forward; these results, however, 
Table 4 Outcome of clonidine intervention - cardiovascular variables

Baseline Week 8 (during treatment)

\section{Supine}

Heart rate - beats/min

Clonidine group, mean
Placebo group, mean
Difference (95\% Cl)
p-value (clonidine vs. placebo)
SBP - mmHg
Clonidine group, mean
Placebo group, mean
Difference (95\% Cl)
p-value (clonidine vs. placebo)

$\begin{array}{ll}70 & 67 \\ 72 & 69 \\ & -2.0(-4.1 \text { to } 0.1) \\ & \\ & \end{array}$

$\mathrm{MBP}-\mathrm{mmHg}$

Clonidine group, mean
Placebo group, mean
Difference ( $95 \% \mathrm{Cl}$ )
p-value (clonidine vs. placebo)
DBP - mmHg

Clonidine group, mean

Placebo group, mean

Difference $(95 \% \mathrm{Cl})$

$\mathrm{p}$-value (clonidine vs. placebo)

$\mathrm{SI}-\mathrm{ml} / \mathrm{m}^{2}$

Clonidine group, mean

Placebo group, mean

Difference $(95 \% \mathrm{Cl})$

p-value (clonidine vs. placebo)

$\begin{array}{ll}65 & 64 \\ 66 & 63 \\ & 0.8(-1.0 \text { to } 2.7) \\ & 0.37\end{array}$

TPRI - $\mathrm{mmHg} / \mathrm{L} / \mathrm{min} / \mathrm{m}^{2}$

Clonidine group, mean
Placebo group, mean
Difference ( $95 \% \mathrm{Cl})$
p-value (clonidine vs. placebo)

$47 \quad 46$

46

46

46

$0.2(-2.1$ to 2.4$)$

0.86

SDNN - ms

Clonidine group, mean

Placebo group, mean

Difference $(95 \% \mathrm{Cl})$

p-value (clonidine vs. placebo)

r-MSSD - ms

Clonidine group, mean
Placebo group, mean
Difference ( $95 \%$ Cl)
p-value (clonidine vs. placebo)
NN50 - \%

Clonidine group, mean
Table 4 Outcome of clonidine intervention - cardiovascular variables (Continued)

\begin{tabular}{|c|c|c|}
\hline Placebo group, mean & 31 & 38 \\
\hline Difference (95 \% Cl) & & $2.2(-3.0$ to 7.3$)$ \\
\hline p-value (clonidine vs. placebo) & & 0.40 \\
\hline \multicolumn{3}{|l|}{ LF-HRV - nu } \\
\hline Clonidine group, mean & 40 & 42 \\
\hline Placebo group, mean & 43 & 38 \\
\hline Difference $(95 \% \mathrm{Cl}$ ) & & $3.7(-0.5$ to 8.0$)$ \\
\hline p-value (clonidine vs. placebo) & & 0.08 \\
\hline \multicolumn{3}{|l|}{ HF-HRV - nu } \\
\hline Clonidine group, mean & 60 & 58 \\
\hline Placebo group, mean & 57 & 62 \\
\hline Difference $(95 \% \mathrm{Cl}$ ) & & $-3.7(-8.0$ to 0.5 \\
\hline p-value (clonidine vs. placebo) & & 0.08 \\
\hline \multicolumn{3}{|l|}{$L F-H R V^{*}-m s^{2}$} \\
\hline Clonidine group, mean & 628 & 679 \\
\hline Placebo group, mean & 451 & 487 \\
\hline Ratio (95 \% Cl) & & $1.4(1.1$ to 1.8$)$ \\
\hline p-value (clonidine vs. placebo) & & 0.007 \\
\hline \multicolumn{3}{|l|}{$\mathrm{HF}-\mathrm{HRV} \mathrm{V}^{*}-\mathrm{ms}^{2}$} \\
\hline Clonidine group, mean & 962 & 961 \\
\hline Placebo group, mean & 600 & 825 \\
\hline Ratio (95 \% Cl) & & $1.2(0.9$ to 1.5$)$ \\
\hline p-value (clonidine vs. placebo) & & 0.28 \\
\hline \multicolumn{3}{|l|}{ Total Power-HRV* - ms ${ }^{2}$} \\
\hline Clonidine group, mean & 1991 & 2053 \\
\hline Placebo group, mean & 1352 & 1638 \\
\hline Ratio (95 \% Cl) & & $1.3(1.0$ to 1.6$)$ \\
\hline p-value (clonidine vs. placebo) & & 0.06 \\
\hline \multicolumn{3}{|l|}{ LF/HF-ratio* } \\
\hline Clonidine group, mean & 0.65 & 0.70 \\
\hline Placebo group, mean & 0.75 & 0.59 \\
\hline Ratio (95 \% Cl) & & $1.2(1.0$ to 1.4$)$ \\
\hline p-value (clonidine vs. placebo) & & 0.09 \\
\hline \multicolumn{3}{|l|}{ LF-SBP - nu } \\
\hline Clonidine group, mean & 39.3 & 38.0 \\
\hline Placebo group, mean & 38.1 & 36.9 \\
\hline Difference (95 \% Cl) & & $1.1(-3.0$ to 5.2$)$ \\
\hline p-value (clonidine vs. placebo) & & 0.60 \\
\hline \multicolumn{3}{|l|}{ LF-SBP* $-\mathrm{mmHgs}^{2}$} \\
\hline Clonidine group, mean & 3.8 & 3.7 \\
\hline Placebo group, mean & 3.0 & 3.2 \\
\hline Ratio (95 \% Cl) & & 1.1 (0.9 to 1.5$)$ \\
\hline p-value (clonidine vs. placebo) & & 0.34 \\
\hline
\end{tabular}

Response to $20^{\circ}$ head-up tilt 
Table 4 Outcome of clonidine intervention - cardiovascular variables (Continued)

\begin{tabular}{|c|c|c|}
\hline \multicolumn{3}{|l|}{ Heart rate - beats/min } \\
\hline Clonidine group, mean & 5.2 & 4.9 \\
\hline Placebo group, mean & 4.8 & 4.9 \\
\hline Difference (95 \% Cl) & & $0.0(-1.1$ to 1.2$)$ \\
\hline p-value (clonidine vs. placebo) & & 0.97 \\
\hline \multicolumn{3}{|l|}{$\mathrm{SBP}-\mathrm{mmHg}$} \\
\hline Clonidine group, mean & 0.74 & -0.59 \\
\hline Placebo group, mean & 0.15 & -0.01 \\
\hline Difference (95 \% Cl) & & $-0.58(-2.2$ to 1.0$)$ \\
\hline p-value (clonidine vs. placebo) & & 0.48 \\
\hline \multicolumn{3}{|l|}{$\mathrm{MBP}-\mathrm{mmHg}$} \\
\hline Clonidine group, mean & 1.19 & 0.61 \\
\hline Placebo group, mean & 0.94 & 1.23 \\
\hline Difference (95 \% Cl) & & $-0.63(-2.1$ to 0.8$)$ \\
\hline p-value (clonidine vs. placebo) & & 0.39 \\
\hline \multicolumn{3}{|l|}{$\mathrm{DBP}-\mathrm{mmHg}$} \\
\hline Clonidine group, mean & 1.13 & 1.2 \\
\hline Placebo group, mean & 1.58 & 1.8 \\
\hline Difference (95 \% Cl) & & $-0.59(-2.0$ to 0.8$)$ \\
\hline p-value (clonidine vs. placebo) & & 0.40 \\
\hline \multicolumn{3}{|l|}{$\mathrm{SI}-\mathrm{ml} / \mathrm{m}^{2}$} \\
\hline Clonidine group, mean & -5.9 & -4.5 \\
\hline Placebo group, mean & -5.1 & -5.3 \\
\hline Difference (95 \% Cl) & & $0.9(-0.4$ to 2.1$)$ \\
\hline p-value (clonidine vs. placebo) & & 0.17 \\
\hline \multicolumn{3}{|l|}{$\mathrm{TPRI}-\mathrm{mmHg} / \mathrm{L} / \mathrm{min} / \mathrm{m}^{2}$} \\
\hline Clonidine group, mean & 0.66 & 0.44 \\
\hline Placebo group, mean & 0.60 & 0.62 \\
\hline Difference (95 \% Cl) & & $-0.18(-0.47$ to 0.11$)$ \\
\hline p-value (clonidine vs. placebo) & & 0.22 \\
\hline \multicolumn{3}{|l|}{ SDNN - ms } \\
\hline Clonidine group, mean & -5.1 & -7.9 \\
\hline Placebo group, mean & -4.4 & -0.7 \\
\hline Difference (95 \% Cl) & & $-7.2(-16.0$ to 1.6$)$ \\
\hline p-value (clonidine vs. placebo) & & 0.11 \\
\hline \multicolumn{3}{|l|}{ r-MSSD - ms } \\
\hline Clonidine group, mean & -18 & -24 \\
\hline Placebo group, mean & -16 & -17 \\
\hline Difference (95 \% Cl) & & $-7.6(-19.6$ to 4.4$)$ \\
\hline p-value (clonidine vs. placebo) & & 0.11 \\
\hline \multicolumn{3}{|l|}{ pNN50 - \% } \\
\hline Clonidine group, mean & -14 & -11 \\
\hline Placebo group, mean & -9 & -13 \\
\hline Difference (95 \% Cl) & & $1.2(-3.1$ to 5.4$)$ \\
\hline
\end{tabular}

Table 4 Outcome of clonidine intervention - cardiovascular variables (Continued)

\begin{tabular}{lll}
\hline p-value (clonidine vs. placebo) & & 0.59 \\
LF-HRV - nu & \\
Clonidine group, mean & 8.3 & 6.1 \\
Placebo group, mean & 6.7 & 9.2 \\
Difference (95\% Cl) & & $-3.1(-7.4$ to 1.1) \\
p-value (clonidine vs. placebo) & 0.15
\end{tabular}

HF-HRV - nu

$\begin{array}{lll}\text { Clonidine group, mean } & -8.3 & -6.1 \\ \text { Placebo group, mean } & -6.7 & -9.2 \\ \text { Difference }(95 \% \mathrm{Cl}) & & 3.1(-1.1 \text { to } 7.4) \\ \text { p-value (clonidine vs. placebo) } & 0.15\end{array}$

$L F-H R V^{\#}-m s^{2}$

Clonidine group, mean $\quad-320 \quad-161$

Placebo group, mean $\quad-176 \quad-171$

n.a. $\quad$ n.a.

p-value (clonidine vs. placebo) $\quad 0.87$

$H F-H R V^{\#}-m s^{2}$

Clonidine group, mean $\quad-828 \quad-640$

Placebo group, mean $\quad-523 \quad-629$

n.a. n.a.

p-value (clonidine vs. placebo) $\quad 0.99$

Total Power-HRV $\mathrm{V}^{\#} \mathrm{~ms}^{2}$

Clonidine group, mean

$-1107 \quad-790$

Placebo group, mean

$-668-736$

n.a.

n.a.

p-value (clonidine vs. placebo)

0.78

LF/HF-ratio

$\begin{array}{lll}\text { Clonidine group, mean } & 0.35 & 0.34\end{array}$

$\begin{array}{lll}\text { Placebo group, mean } & 0.44 & 0.55\end{array}$

Difference $(95 \% \mathrm{Cl})$

$-0.21(-0.46$ to 0.04$)$

$\mathrm{p}$-value (clonidine vs. placebo)

0.09

LF-SBP - nu

$\begin{array}{lll}\text { Clonidine group, mean } & 2.5 & 4.4\end{array}$

Placebo group, mean $\quad 3.2 \quad 3.7$

Difference $(95 \% \mathrm{Cl})$

0.7 ( -2.4 to 3.8$)$

p-value (clonidine vs. placebo)

0.66

LF-SBP - mmHgs ${ }^{2}$

Clonidine group, mean $\quad-2.6 \quad-1.0$ 
Table 4 Outcome of clonidine intervention - cardiovascular variables (Continued)

\begin{tabular}{|c|c|c|}
\hline Placebo group, mean & -0.6 & -0.2 \\
\hline Difference (95 \% Cl) & & $-0.7(-1.7$ to 0.3$)$ \\
\hline p-value (clonidine vs. placebo) & & 0.17 \\
\hline
\end{tabular}

Missing values were imputed based on the principle of last observation carried forwards. Thus, all calculations are based on 120 individuals (60 in each intervention group). Means and differences at week 8 are estimated from the parameters of the general linear model

For variables annotated with a *, modeling was performed on In-transformed variables; all means are based on back-transformation of the variables, and ratios instead of differences are reported. For variables annotated with a \#, modeling was performed on square root-transformed variables; all means are based on back-transformation of the variables, but neither differences nor ratios can be computed, as indicated with the label n.a. (not applicable). $\mathrm{Cl}=$ Confidence Interval; SBP = Systolic Blood Pressure; MBP = Mean arterial Blood Pressure; DBP = Diastolic Blood Pressure; $\mathrm{SI}=$ Stroke Index; TPRI = Total Periferal Resistance Index; $\mathrm{RRI}=\mathrm{R}-\mathrm{R}$ Interval; $\mathrm{HRV}=$ heart rate variability; $\mathrm{HF}=\mathrm{High}$ Frequency; $L F=$ Low Frequency; SDNN = standard deviation of all RR-intervals; pNN50 = the proportion of successive RRls with adifference greater than $50 \mathrm{~ms}$; $r-M S S D=$ the square root of the mean square differences of successive RRls; $n u=$ normalized units; n.a. = not applicable because of square root transformation of variables; $n=$ number of patients, for most variables equal to 60 because of imputation

might suggest an enhancement of sympathetic heart rate modulation, resembling the effects of clonidine in essential hypertension [48]. This is in contrast to effects of clonidine in healthy subjects [44]. A previous study suggests early sympathetic baroreceptor activation and diminished baroreceptor reserve in CFS [11]. We speculate that clonidine, by way of reducing sympathetic tone (as evident from the catecholamine-lowering effect), might in fact increase the sympathetic nervous system modulatory effects [49].

Taken together, the findings presented in this study suggest an alteration of clonidine pharmacodynamics in CFS. One possible explanation is genetically determined differences of the alpha $\mathrm{a}_{2 \mathrm{~A}}$ receptor protein, which is the ligand for clonidine. A single nucleotide polymorphism (SNP) (rs1800544) in the alpha $_{2 \mathrm{~A}}$ receptor gene implies substitution of guanine $(\mathrm{G})$ for cytosine $(\mathrm{C})$ at position 1291, and has functional consequences [18]. However, the genotype frequencies among CFS patients and a comparable group of healthy controls were almost identical, and subgroup analysis based on genotype revealed no differences in response to treatment. Another possible explanation is altered expression of adrenoceptors, as has previously been demonstrated in CFS [50] as well as in other conditions with high levels of catecholamines [51].

The possibility of increased long-term cardiovascular risk in CFS patients remains a concern [52]. In addition to increased sympathetic nervous activity, CFS patients are also characterized by slight inflammatory activation [28] and elevated nocturnal blood pressure and heart rate [53], which in turn are associated with development of atherosclerosis. Further research is warranted to clarify the eventual need of prophylactic measures.
A possible limitation of this study is the wide inclusion criteria and no a priori-definition of the degree of school absenteeism necessary to fulfil the diagnostic criteria, which might have obscured results applying to a subgroup only. However, the study population corresponds closely to the population who is diagnosed as CFS by pediatricians; thus, we assume the external validity to be strong. Furthermore, subgrouping based upon the 1994 CFS case definition did not change the results. We have not done subgrouping based on caffeine use. Another limitation of this study is the $4 \mathrm{~min}$ epochs used for time-domain analyses of heart rate variability, as opposed to the $5 \mathrm{~min}$ epochs recommended [32]. It is considered inappropriate to compare time-domain indices (especially SDNN) obtained from recordings of different durations; while the present study does not violate this principle, caution should be shown when comparing our results to other studies. Strengths of this study include high compliance and low drop-out-rates, and the successful blinding of all (staff and patients) clinically involved in the study.

\section{Conclusions}

Low-dose clonidine reduces catecholamine levels in adolescent CFS. However, the effects on cardiovascular autonomic control are sparse, and clonidine does not improve symptoms of orthostatic intolerance.

\section{Abbreviations \\ BP: Blood pressure; CFS: Chronic fatigue syndrome; HF: High frequency; HR: Heart rate; HRV: Heart rate variability; HUT: Head-up tilt test; LF: Low frequency; RRI: Instantaneous RR intervals; SBP: Systolic blood pressure; SNP: Single nucleotide polymorphism.}

\section{Competing interests}

The authors declare that they have no competing interests.

\section{Authors' contributions}

EF, DS and AW collected clinical data, contributed to study design and participated in data analyses. AMA, JG and KG carried out laboratory analyses. PCR and JPS contributed to study design. ES supervised data analyses. VBW conceived of the study, contributed to study design and participated in data analyses. All authors contributed to data interpretation and drafting of the manuscript. All authors approved the final manuscript as submitted.

\section{Acknowledgements}

We thank Kari Gjersum for secretary assistance; Hamsana Chandrakumar, Esther Gangsø, Anne Marie Halstensen, Adelheid Holm, Berit Widerøe Njølstad, Pelle Rohdin, and Anna Marie Thorendal Ryenbakken for practical assistance; Berit Bjelkåsen for development of the computerized randomization procedure; Liv Thrane Bjerke for pharmacy services; Gaute Døhlen, Bjørn Bendz, Knut Engedal, and Ola Didrik Saugstad for study monitoring; all referring units; and finally all participants and their parents/ next-of-kin.

The study was funded by: Health South-East Hospital Trust; The University of Oslo; Oslo and Akershus University College of Applied Sciences; The Norwegian Competence Network of Paediatric Pharmacotherapy; Simon Fougner Hartmann's Family Foundation; Eckbo's Family Foundation.

\section{Author details}

${ }^{1}$ Institute of Clinical Medicine, Medical Faculty, University of Oslo, P.O.Box 1171, Blindern 03180slo, Norway. ${ }^{2}$ Department of Anaesthesiology and 
Critical Care, Oslo University Hospital, P.O.Box 4950, Nydalen 0424Oslo, Norway. ${ }^{3}$ Department of Paediatrics, Oslo University Hospital, P.O.Box 4950, Nydalen 04240slo, Norway. ${ }^{4}$ Department of Paediatrics, Lillehammer County Hospital, P.O.Box 1042381 Brumunddal, Norway. Institute of Nursing Sciences, Oslo and Akershus University College of Applied Sciences, P.O. Box 4 St., Olavs plass 01300slo, Norway. ${ }^{6}$ Department of Pharmacology, Oslo University Hospital, P.O.Box 4950, Nydalen 0424Oslo, Norway. ${ }^{7}$ National Institute of Occupational Health, P.O Box 8149, Dep 0033Oslo, Norway. ${ }^{8}$ Department of Biosciences, University of Oslo, P.O.Box 1066, Blindern 03160slo, Norway. ${ }^{9}$ Section of Specialized Endocrinology, Department of Endocrinology, Oslo University Hospital Rikshospitalet, P.O.Box 4950, Nydalen 04240 slo, Norway. ${ }^{10}$ Department of Paediatrics, Johns Hopkins University School of Medicine, 200 N. Wolfe Street, Baltimore, MD 21287, USA.

${ }^{11}$ Department of Paediatrics, Medical University of South Carolina, 169 Ashley Avenue, Charleston, SC 29425, USA. ${ }^{12}$ Department of Pharmaceutical Science, University of Oslo, P.O.Box 1068, Blindern 03160slo, Norway. ${ }^{13}$ Norwegian Institute of Public Health, P.O.Box 4404, Nydalen 0403Oslo, Norway. ${ }^{14}$ Department of Paediatrics, Akershus University Hospital, P.O.Box 10001478 Lørenskog, Norway.

\section{Received: 7 September 2014 Accepted: 20 August 2015}

\section{Published online: 10 September 2015}

\section{References}

1. Nijhof SL, Maijer K, Bleijenberg G, Uiterwaal CS, Kimpen JL, van der Putte EM. Adolscent chronic fatigue syndrome: prevalence, incidence, and morbidity. Pediatrics. 2011;127:e1169-75.

2. Crawley E. The epidemiology of chronic fatigue syndrome/myalgic encephalitis in children. Arch Dis Child. 2014;99:171-4.

3. Rowe KS. Double-blind randomized controlled trial to assess the efficacy of intravenous gammaglobulin for the management of chronic fatigue syndrome in adolescents. J Psychiatr Res. 1997;31:133-47.

4. Hoad A, Spickett G, Elliott J, Newton J. Postural orthostatic tachycardia syndrome is an under-recognized condition in chronic fatigue syndrome. QJM. 2008;101:961-5.

5. Stewart JM, Gewitz MH, Weldon A, Arlievsky N, Li K, Munoz J. Orthostatic intolerance in adolescent chronic fatigue syndrome. Pediatrics. 1999;103:116-21.

6. Stewart JM, Gewitz MH, Weldon A, Munoz J. Patterns of orthostatic intolerance: The orthostatic tachycardia syndrome and adolescent chronic fatigue. J Pediatrics. 1999;135:218-25.

7. Okamoto LE, Raj SR, Peltier A, Gamboa A, Shibao C, Diedrich A, et al. Neurohumoral and haemodynamic profile in postural tachycardia and chronic fatigue syndromes. Clin Sci. 2012;122:183-92.

8. Bou-Holaigah I, Rowe PC, Kan J, Calkins H. The relationship between neurally mediated hypotension and the chronic fatigue syndrome. JAMA. 1995;274:961-7.

9. Wyller VB, Due R, Saul JP, Amlie JP, Thaulow E. Usefulness of an abnormal cardiovascular response during low-grade head-up tilt-test for discriminating adolescents with chronic fatigue from healthy controls. Am J Cardiol. 2007:99:997-1001.

10. Wyller VB, Barbieri R, Thaulow E, Saul JP. Enhanced vagal withdrawal during mild orthostatic stress in adolescents with chronic fatigue. Ann Noninvasive Electrocardiol. 2008;13:67-73.

11. Wyller VB, Barbieri R, Saul P. Blood pressure variability and closed-loop baroreflex assessment in adolescent chronic fatigue syndrome during supine rest and orthostatic stress. Eur J Appl Physiol. 2011;111:497-502.

12. Boneva RS, Decker MJ, Maloney EM, Lin JM, Jones JF, Helgason HG, et al. Higher heart rate and reduced heart rate variability persist during sleep in chronic fatigue syndrome: a population-based study. Auton Neurosci. 2007;137:94-101.

13. Lewis I, Pairman J, Spickett G, Newton JL. Clinical characteristics of a novel subgroup of chronic fatigue syndrome patients with postural orthostatic tachycardia syndrome. J Intern Med. 2013;273:501-10.

14. Szabo B. Imidazoline antihypertensive drugs: a critical review on their mechanism of action. Pharmacol Ther. 2002;93:1-35.

15. Anavekar SN, Jarrott B, Toscano M, Louis WJ. Pharmacokinetic and pharmacodynamic studies of oral clonidine in normotensive subjects. Eur $\rfloor$ Clin Pharmacol. 1982;23:1-5.

16. Cividjian A, Toader E, Wesseling KH, Karemaker JM, McAllen R, Quintin L. Effect of clonidine on cardiac baroreflex delay in humans and rats. Am J Physiol Regul Integr Comp Physiol. 2011;300:949-57.
17. Fagermoen E, Sulheim D, Winger A, Andersen AM, Vethe NT, Saul JP, et al. Clonidine in the treatment of adolescent chronic fatigue syndrome: a pilot study for the NorCAPITAL trial. BMC Res Notes. 2012;5:418.

18. Small KM, Liggett SB. Identification and functional characterixation of alpha2-adrenoceptor polymorphisms. Trend Pharm Sci. 2001;22:471-7.

19. National Institute for Health and Clinical Excellence. Chronic fatigue syndrome/myalgic encephalomyelitis (or encephalopathy). Diagnosis and management of CFS/ME in adults and children. NICE clinical guideline 2007, no. 53. London, England: Royal College of Pediatrics and Child Health.

20. Royal College of Paediatrics and Child Health. Evidence Based Guideline for the Management of CFS/ME in Children and Young People. London England: National Institute for Health and Clinical Excellence; 2004

21. Sulheim D, Hurum H, Helland IB, Thaulow E, Wyller VB. Concurrent improvement of circulatory abnormalities and clinical symptoms in adolescent chronic fatigue syndrome. Biopsychosoc Med. 2012;6:10.

22. Tsunoda M. Recent advances in methods for the analysis of catecholamines and their metabolites. Anal Bioanal Chem. 2006;386:506-14.

23. Kågedal B, Goldstein DS. Catecholamines and their metabolites. J Chromatogr. 1988;29:177-233.

24. Hjemdahl P. Catecholamine measurements by high-performance liquid chromatography. Am J Physiol. 1984;247:E13-20.

25. Müller C, Ramic M, Harlfinger S, Hünseler C, Theisohn M, Roth B. Sensitive and convenient method for the quantification of clonidine in serum of pediatric patients using liquid chromatography/tandem mass spectrometry. J Chromatogr A. 2007;1139:221-7.

26. US Department of Health and Human Services, Food and Drug Administration. Guidance for Industry. Bioanalytic method validation. MD, USA, 2001.http:// www.fda.gov/downloads/Drugs/GuidanceComplianceRegulatorylnformation/ Guidances/UCM070107.pdf (2015.02.18).

27. Olsen MB, Jacobsen LM, Schistad El, Pedersen LM, Rygh $L$, Røe C, et al. Pain intensity the first year after lumbar disc herniation is associated with the A118G polymorphism in the opioid receptor mu 1 gene: evidence of a sex and genotype interaction. J Neurosci. 2012;32:9831-4.

28. Sulheim D, Fagermoen E, Winger A, Andersen AM, Godang K, Müller F, et al. Disease mechanisms and clonidine treatment in adolescent chronic fatigue syndrome: a combined cross-sectional and randomized clinical trial. JAMA Pediatr. 2014;168:351-60.

29. de Jong-de Vos van Steenwijk CC, Wieling W, Johannes JM, Harms MP, Kuis W, Wesseling $\mathrm{KH}$. Incidence and hemodynamic characteristics of near-fainting in healthy6- to 16-year old subjects. J Am Coll Cardiol. 1995;25:1615-21.

30. Fortin J, Habenbacher W, Heller A, Hacker A, Grüllenberger R, Innerhover J, et al. Non-invasive beat-to-beat cardiac output monitoring by an improved method of transthoracic bioimpedance measurement. Comput Biol Med. 2006;36:1185-203.

31. Bianchi AM, Mainardi LT, Meloni C, Chierchia S, Cerutti S. Continuous monitoring of the sympatho-vagal balance through spectral analysis. Eng Med Biol Mag. 1997;16:64-73.

32. Task force of the European society of cardiology and the North American society of pacing electrophysiology. Heart rate variability. Standards of measurement, physiological interpretation, and clinical use. Circulation. 1996:93:1043-65

33. Malpas S. Neural influences on cardiovascular variability: possibilities and pitfalls. Am J Physiol Heart Circ Physiol. 2002;282:H6-20.

34. Suarez GA, Opfer-Gehrking TL, Offord KP, Atkinson EK, O'Brien PC, Low PA. The autonomic symptom profile: a new instrument to assess autonomic symptoms. Neurology. 1999;52:523-8.

35. Wagner D, Nisenbaum R, Heim C, Jones JF, Unger ER, Reeves WC. Psychometric properties of the CDC symptom inventory for assessment for Chronic Fatigue Syndrome. Popul Health Metr. 2005;3:8.

36. Fukuda K, Straus SE, Hickie I, Sharpe MC, Dobbins JG, Komaroff A. The chronic fatigue syndrome: a comprehensive approach to its definition and study. Ann Int Med. 1994;121:953-9.

37. Vickers AJ, Altman DG. Statistics notes: Analysing controlled trials with baseline and follow up measurements. BMJ. 2001;323:1123-4.

38. Pagani M, Lucini D, Mela GS, Langewitz W, Malliani A. Sympathetic overactivity in subjects complaining of unexplained fatigue. Clin Sci. 1994;87:655-61.

39. Stewart J, Weldon A, Arlievsky N, Li K, Munoz J. Neurally mediated hypotension and autonomic dysfunction measured by heart rate variability during head-up tilt testing in children with chronic fatigue syndrome. Clin Auton Res. 1998:8:221-30. 
40. Timmers HJ, Wieling W, Soetekouw PM, Bleijenberg G, Van Der Meer JW, Lenders JW. Hemodynamic and neurohumoral responses to head-up tilt in patients with chronic fatigue syndrome. Clin Auton Res. 2002;12:273-80.

41. Wyller VB, Saul JP, Walløe L, Thaulow E. Sympathetic cardiovascular control during orthostatic stress and isometric exercise in adolescent chronic fatigue syndrome. Eur J Appl Physiol. 2008;102:623-32.

42. De Becker $P$, Dendale $P$, De Meirleir K, Campine I, Vandenborne K, Hagers Y. Autonomic testing in patients with chronic fatigue syndrome. Am J Med. 1998;105:22S-6.

43. Grouzmann E, Lamine F. Determination of catecholamines in plasma and urine. Best Pract Res Clin Endocrinol Metab. 2013;5:713-23.

44. Lazzeri C, La Villa G, Mannelli M, Janni L, Franchi F. Effects of acute clonidine administration on power spectral analysis of heart rate variability in healthy humans. J Auton Pharmacol. 1998;18:307-12.

45. Anavekar SN, Howes LG, Jarrott B, Syrjanen M, Conway EL, Louis WJ. Pharmacokinetics and antihypertensive effects of low dose clonidine during chronic therapy. J Clin Pharmacol. 1989;29:32.

46. Arndts D, Doevendans J, Kiersten R, Heintz B. New aspects of the pharmacokinetics and pharmacodynamics of clonidine in man. Eur J Clin Pharmacol. 1983;24:21-30.

47. Veith RC, Beset JD, Halter JB. Dose-dependent supression of norepineprhine appearance rate in plasma by clonidine in man. J Clin Endocrinol Metab. 1984;59:151.

48. Lazzeri C, La Villa G, Mannelli M, Janni L, Barletta G, Montano N, et al. Effects of clonidine on power spectral analysis of heart rate variability in mild essential hypertension. J Auton Nerv Syst. 1998;74:152-9.

49. Saul JP. Beat-to-beat variations of heart rate reflect modulation of cardiac autonomic outflow. News Physiol Sci. 1990;5:32-7.

50. Light AR, Bateman L, Jo D, Hughen RW, Vanhaitsma TA, White AT, et al. Gene expression alterations at baseline and following moderate exercise in patients with Chronic Fatigue Syndrome and Fibromyalgia Syndrome. J Int Med. 2012;271:64-81.

51. Streeten $\mathrm{DH}$, Anderson Jr GH. Mechanisms of orthostatic hypotension and tachycardia in patients with pheochromocytoma. Am J Hypertens. 1996;9:760-9.

52. Zhou Y, Xie G, Wang J, Yang S. Cardiovascular risk factors significantly correlate with autonomic nervous system activity in children. Can J Cardiol. 2012;28:477-82.

53. Hurum H, Sulheim D, Thaulow E, Wyller VB. Elevated nocturnal blood pressure and heart rate in adolescent chronic fatigue syndrome. Acta Paediatr. 2011;100:289-92.

\section{Submit your next manuscript to BioMed Central and take full advantage of:}

- Convenient online submission

- Thorough peer review

- No space constraints or color figure charges

- Immediate publication on acceptance

- Inclusion in PubMed, CAS, Scopus and Google Scholar

- Research which is freely available for redistribution 